\title{
Current approaches for assisted oocyte maturation in camels
}

\author{
Islam M. Saadeldin ${ }^{1,2}$ and Jongki Cho ${ }^{1, *}$ \\ ${ }^{1}$ Lab. of Theriogenology, College of Veterinary Medicine, Chungnam National University, Daejeon 34134, Korea \\ ${ }^{2}$ Department of Physiology, Faculty of Veterinary Medicine, Zagazig University, Zagazig 44519, Egypt
}

Received September 16, 2021

Revised September 17, 2021

Accepted September 17, 2021

*Correspondence

Jongki Cho

E-mail: cjki@cnu.ac.kr

ORCID

https://orcid.org/0000-0002-8431-0457

\begin{abstract}
Camel (camelus dromedarius) is a unique large mammalian species that can survive harsh environmental conditions and produce milk, meat, and wool. Camel reproduction is inferior when compared to other farm animal species such as cattle and sheep. Several trials have been reported to increase camel reproduction and production through assisted reproductive techniques (ARTs) such as in vitro fertilization and cloning. For these reasons, obtaining enough mature oocytes is a cornerstone for ARTs. This demand would be improved by the oocyte in vitro maturation (IVM) systems. In this review, the current approaches and views from different laboratories using ARTs and the IVM to produce embryos in vitro in camel species. For the last two decades, conventional IVM system was the common approach, however, recently the bi-phasic IVM system has been introduced and showed promising improvement in IVM of camel oocytes. Detailed studies are needed to understand camel meiosis and IVM to efficiently increase the production of this species.
\end{abstract}

Keywords: blastocyst, camel, cumulus cells, in vitro maturation, oocytes

\section{INTRODUCTION}

According to Food and Agriculture Organization (FAO), worldwide demand for meat will increase by $40 \%$ by the year 2050 . To this end, several strategies, and approaches to increase the livestock population are being promoted. Reproductive success in livestock ensures the continuation, survival, and conservation of species, and by extension of food security through the availability of more food of animal origin. To maximize productivity and to address several reproductive challenges, assisted reproductive technologies (ARTs) have come to a rescue (Comizzoli et al., 2018; Herrick, 2019; Skidmore, 2019).

The dromedary camel (Camelus dromedarius), with its natural ability to produce quality meat, milk and fiber under very hot and most hostile climatic condition (Abri and Faye, 2019), is reproductively weak (Skidmore, 2003; Skidmore, 2019) and has received the least attention among livestock (Russo et al., 2014; Singh et al., 2019). Few important updates on ARTs in camel were recently reviewed by (Singh et al., 2019; Skidmore, 2019), and as stated, only few research centers are working on camel reproduction, and majorly the male camel. Even at that, camel oocyte maturation research is still fallow and the success rate of ARTs is still very slow and low (Abdelkhalek et al., 2017; Fathi et al., 2018; Moawad et al., 2020; Saadeldin et al., 2019; Yaqoob et al., 2017).

One major challenge that has not been researched in camel oocyte maturation is the spontaneous meiotic resumption. When immature oocytes leave the natural 
follicular environment and are cultured in vitro, they spontaneously resume meiosis because of absence of inhibitory signals (Edwards, 1965; Albuz et al., 2010). This sudden meiotic resumption causes loss of cumulus-oocyte communication (Wert and Larsen, 1989) which is crucial for oocyte health, metabolism, and acquisition of developmental competence (Barrett and Albertini, 2010; Tukur et al., 2020a). Eventually, oocytes will have a premature maturation and sadly, these prematurely developed oocytes, even though they appear morphologically normal, are not competent. This issue has been the subject of numerous earlier and recent studies (Lonergan et al., 2000; Gilchrist, 2011; Caballero et al., 2020).

Apart from the inherent fertility problem in the female camel, scarcity of camel ovary (and consequently, oocyte) partly contributes to slow development in camel IVM research. Since the slaughter of fertile female camel is restricted, this made some researchers to consider oocyte cryopreservation as option for in vitro embryo production (Fathi et al., 2018). However, a comprehensive study using freshly obtained camel oocytes for IVM research will help researchers to gain better understanding of camel oocyte in vitro maturation, develop standard protocol, and increase the rate of camel embryo production. Considering the gradual improvement and breakthrough in the IVM of other livestock species and human (Caballero et al., 2020; Vuong et al., 2020), would be a paradigm to improve camel IVM after previous work by various researchers (Mesbah et al., 2016; Yaqoob et al., 2017; Saadeldin et al., 2019).

\section{Advances in in vitro oocyte maturation}

In vitro maturation of oocyte was firstly demonstrated in 1935 by (Pincus and Enzmann, 1935) in an experiment involved rabbit oocytes. Interestingly, their first observation was the spontaneous meiotic resumption of oocytes after leaving the follicle. Their work clearly showed the possibility of obtaining successful maturation and fertilization of oocytes in vitro. All later IVM works were built upon their discovery. The report of Chang in 1955 further supported the earlier findings of Pincus (Chang, 1955). Significantly, the observation that oocyte maturation to the MII stage can be achieved without hormonal stimulation led to deeper investigation of IVM as an alternative and safer approach to IVF.

Inspired by Pincus's work, Edwards in 1956 further demonstrated IVM in different mammalian species including mice, pigs, cows, sheep, rhesus monkey and human (Edwards, 1965). Another significant advances recorded was the production of live mouse (Chang, 1955), and live human from the fertilization of in vitro grown oocytes (Cha et al., 1991). In domestic animals (goat, sheep, cattle, swine, and horse) production of embryos from in vitro matured oocytes has been a routine practice, but success rates are low (Kruip et al., 1991; Lonergan and Fair, 2016).

Another attempt to optimize oocyte development in vitro was the introduction of a two-step culture protocol by Eppig and O'Brien. This protocol involved in vitro culture of the ovary of newborn mice after isolation of the oocyte-granulosa complexes for a second culture. Unfortunately, only $0.5 \%$ of transferred embryos were survived (Eppig and O'Brien, 1996). This protocol was later improved (O'Brien et al., 2003).

It is hypothesized that this temporary delay of meiotic resumption could mimic the natural follicular environment and improve the developmental competence of in vitro matured oocytes (Caballero et al., 2020). Several approaches have been examined to delay oocyte meiotic resumption. These include blockage of cAMP signals, modulation of cAMP concentration (Lonergan et al., 2000; Albuz et al., 2010; Li et al., 2016; Soto-Heras et al., 2019a), inhibition of key molecules such as cyclindependent kinase 1 (CDK1) with roscovitine, and rho associated kinase with Y-27632 (Duan et al., 2014; Zhang et al., 2014; Zhang et al., 2017; Maziero et al., 2020; Zhu et al., 2020), use of adenosine (Caballero et al., 2020) and the inhibition of phosphodiesterase 3A by IBMX or Ctype natriuretic peptide (Albuz et al., 2010; Sanchez et al., 2019; Soto-Heras et al., 2019a) and several other approaches.

Rho-associated protein kinases (ROCK) inhibitor, Y-27632, was used to improve blastocyst yield in human embryos (Huang et al., 2016). The Rho kinase is involved in many cellular functions and has been shown to be important for oocyte meiotic progression, and embryonic development (Arayatham et al., 2017). Short to long-term inhibition of ROCK activity was done and their consequent effects on camel oocyte maturation and gene expression were evaluated.

The sudden meiotic resumption that was earlier observed in IVM (Pincus and Enzmann, 1935; Edwards, 1965) causes loss of cumulus-oocyte communication (Wert and 
Larsen, 1989) which is crucial for oocyte health, metabolism, and acquisition of developmental competence (Barrett and Albertini, 2010). It therefore became clear that in vitro matured oocytes suffer premature development and inability to undergo important physiological and morphological changes that are required to achieve competency (Assey et al., 1994). Hence, control of oocyte meiotic arrest and resumption could make IVM closer to the in vivo maturation. This prompted some researchers to develop IVM condition where oocyte meiotic arrest is maintained at the GV stage i.e. preventing spontaneous maturation (Sirard, 1990; Fulka et al., 1991; Lonergan et al., 1997; Mermillod et al., 2000). Although meiotic arrest was achieved, the inadequacy of this method was that the subsequent development of the oocytes after the period of inhibition was not reported (Lonergan et al., 1997).

The biphasic IVM approach involves temporary delay in meiosis resumption (holding the oocyte at GV stage in vitro) in a pre-maturation phase using meiotic inhibitors before submission to normal in vitro maturation (Lonergan et al., 2000; Sanchez et al., 2019). This is an improvement on the previous methods of sustaining meiotic arrest in
IVM (Caballero et al., 2020).

As stated earlier, the dromedary camel has low reproductive efficiency and efforts to improve this is slow and low compared to other species (Skidmore, 2003; Singh et al., 2019; Skidmore, 2019). Few research on IVM of dromedary camel oocytes have been reported and it is still at the early stage (Yaqoob et al., 2017; Fathi et al., 2018; Saadeldin et al., 2019). One of the areas that requires indepth research in camel oocyte maturation is the spontaneous meiotic resumption which is a common challenge in IVM of all species. Since this area is barren in camel oocyte research, it is therefore the focus of this thesis. Table 1 summarizes the approaches used for camel IVM using either single phase or bi-phasic IVM system.

\section{CONCLUSION AND FUTURE PERSPECTIVES}

Since the recognition of in vitro maturation as a simple, promising, non-invasive, and cheaper procedure for embryo production in ARTs, extensive research has been conducted on different species. Among livestock, because both bovine and porcine have received most attention in

Table 1. The current approaches for camel cumulus-oocyte complex in vitro maturation (IVM)

\begin{tabular}{|c|c|c|c|c|}
\hline IVM type & Main supplement & Effects & In vitro embryo development & References \\
\hline & All-trans retinoic acid & $\begin{array}{l}\text { Increased TGF } \beta \text { expression } \\
\text { in cumulus cells and } \\
\text { increased MII oocytes }\end{array}$ & No effect on blastocyst $\%$ after PA & Saadeldin et al., 2019 \\
\hline & $10 \%$ follicular fluid & $\begin{array}{l}\text { Improved cumulus expansion } \\
\text { and MII oocytes }\end{array}$ & No effect on blastocyst \% after PA & Yaqoob et al., 2017 \\
\hline & $15 \%$ fetal calf serum & Optimizing IVM duration & NA & Russo et al., 2014 \\
\hline & $20 \mathrm{ng} / \mathrm{mL}$ EGF & $\begin{array}{l}\text { Optimizing IVM } \\
\text { Improved MII oocytes }\end{array}$ & NA & Wani and Wernery, 2010 \\
\hline & $0.5 \mathrm{mg} / \mathrm{mL} \mathrm{L}$-carnitine & Improved MII oocytes & Improved blastocysts after IVF & Fathi and El-Shahat, 2017 \\
\hline & $50 \mu \mathrm{g} / \mathrm{mL}$ of vitamin C & Improved MII oocytes & NA & Al-Malikey and Al-Delemi, 2021 \\
\hline Biphasic IVM & $50 \mu \mathrm{M}$ Roscovitine for $24 \mathrm{~h}$ & GVBD inhibition & Increased blastocyst formation after PA & Wani and Hong, 2020 \\
\hline & $\begin{array}{l}10 \mu \mathrm{M} \text { ROCK inhibitor } \\
(\mathrm{Y}-27632) \text { for } 4 \mathrm{~h}\end{array}$ & $\begin{array}{l}\text { Improved cumulus expansion, } \\
\text { reduced apoptosis, and } \\
\text { increased MII oocytes }\end{array}$ & NA & Tukur et al., 2020b \\
\hline
\end{tabular}

GVBD, Germinal vesicle breakdown; IVF, In vitro fertilization; MII, meiotic II, $1^{\text {st }}$ polar body extrusion; NA, Not applicable; PA, parthenogenetic activation; ROCK, Rho-associated protein kinases. 
this area (Bahrami et al., 2019) and in the recent years, notable improvement and advances in IVM technique have been demonstrated. The different biphasic IVM methods reported in recent studies have recorded amazing outcomes in human (Sanchez et al., 2019; Vuong et al., 2020) and livestock species (Soto-Heras et al., 2019b; Caballero et al., 2020), and recently in camels (Tukur et al., 2020b; Wani and Hong, 2020). Further investigations about camel meiosis is required to establish an efficient in vitro maturation system in this unique species.

\section{CONFLICTS OF INTEREST}

No potential conflict of interest relevant to this article was reported.

\section{ACKNOWLEDGEMENTS}

This research was supported by Brain Pool program funded by the Ministry of Science and ICT through the National Research Foundation of Korea (grant number: 2021H1D3A2A02040098). The authors thank the staff members at Faculty of Veterinary Medicine, Zagazig University.

\section{AUTHOR CONTRIBUTIONS}

\author{
Conceptualization: IMS and JC \\ Investigation: IMS and JC \\ Methodology: IMS and JC \\ Writing - original draft: IMS and JC \\ Writing - review \& editing: IMS and JC
}

\section{AUTHOR'S POSITION AND ORCID NO.}

\author{
Saadeldin IM, Associate Professor, \\ https://orcid.org/0000-0002-7633-730X \\ Cho J, Professor, \\ https://orcid.org/0000-0002-8431-0457
}

\section{REFERENCES}

Abdelkhalek AE, Gabr SA, Khalil WA, Shamiah SM, Pan L, Qin G, Farouk MH. 2017. In vitro production of Sudanese camel (Camelus dromedarius) embryos from epididymal spermatozoa and follicular oocytes of slaughtered animals. Pol. J. Vet. Sci. 20:95-101.
Abdoon AS, Kandil OM, Zeng SM, Cui M. 2011. Mitochondrial distribution, ATP-GSH contents, calcium [Ca2+] oscillation during in vitro maturation of dromedary camel oocytes. Theriogenology 76:1207-1214.

Abri MAA and Faye B. 2019. Genetic improvement in dromedary camels: challenges and opportunities. Front. Genet. 10:167.

Al-Malikey KHR and Al-Delemi DHJ. 2021. Effect of vitamin C on in vitro maturation of Iraqi she-camel oocytes. Anbar J. Vet. Sci. 14:68-74.

Albuz FK, Sasseville M, Lane M, Armstrong DT, Thompson JG, Gilchrist RB. 2010. Simulated physiological oocyte maturation (SPOM): a novel in vitro maturation system that substantially improves embryo yield and pregnancy outcomes. Hum. Reprod. 25:2999-3011.

Arayatham S, Tiptanavattana N, Tharasanit T. 2017. Effects of vitrification and a Rho-associated coiled-coil containing protein kinase 1 inhibitor on the meiotic and developmental competence of feline oocytes. J. Reprod. Dev. 63:511-517.

Assey RJ, Hyttel P, Greve T, Purwantara B. 1994. Oocyte morphology in dominant and subordinate follicles. Mol. Reprod. Dev. 37:335-344.

Bahrami M, Morris MB, Day ML. 2019. Amino acid supplementation of a simple inorganic salt solution supports efficient in vitro maturation (IVM) of bovine oocytes. Sci. Rep. 9:11739.

Barrett SL and Albertini DF. 2010. Cumulus cell contact during oocyte maturation in mice regulates meiotic spindle positioning and enhances developmental competence. J. Assist. Reprod. Genet. 27:29-39.

Caballero J, Blondin P, Vigneault C, Sirard MA, Richard FJ. 2020. The use of adenosine to inhibit oocyte meiotic resumption in Bos taurus during pre-IVM and its potential to improve oocyte competence. Theriogenology 142:207-215.

Cha KY, Koo JJ, Ko JJ, Choi DH, Han SY, Yoon TK. 1991. Pregnancy after in vitro fertilization of human follicular oocytes collected from nonstimulated cycles, their culture in vitro and their transfer in a donor oocyte program. Fertil. Steril. 55:109-113.

Chang MC. 1955. The maturation of rabbit oocytes in culture and their maturation, activation, fertilization and subsequent development in the Fallopian tubes. J. Exp. Zool. 128:379-405.

Comizzoli P, Paulson EE, McGinnis LK. 2018. The mutual benefits of research in wild animal species and human-assisted reproduction. J. Assist. Reprod. Genet. 35:551-560.

Duan X, Liu J, Dai XX, Liu HL, Cui XS, Kim NH, Wang ZB, Wang Q, Sun SC. 2014. Rho-GTPase effector ROCK phosphorylates cofilin in actin-meditated cytokinesis during mouse oocyte meiosis. Biol. Reprod. 90:37.

Edwards RG. 1965. Maturation in vitro of mouse, sheep, cow, pig, rhesus monkey and human ovarian oocytes. Nature 208:349-351.

Eppig JJ and O'Brien MJ. 1996. Development in vitro of mouse oocytes from primordial follicles. Biol. Reprod. 54:197-207. 
Fathi M and El-Shahat KH. 2017. L-carnitine enhances oocyte maturation and improves in vitro development of embryos in dromedary camels (Camelus dromedaries). Theriogenology 104:18-22.

Fathi M, Moawad AR, Badr MR. 2018. Production of blastocysts following in vitro maturation and fertilization of dromedary camel oocytes vitrified at the germinal vesicle stage. PLoS One 13:e0194602.

Fathi M, Salama A, El-Shahat KH, El-Sherbiny HR, Abdelnaby EA. 2021. Effect of melatonin supplementation during IVM of dromedary camel oocytes (Camelus dromedarius) on their maturation, fertilization, and developmental rates in vitro. Theriogenology 172:187-192.

Fathi M, Seida AA, Sobhy RR, Darwish GM, Badr MR, Moawad AR. 2014. Caffeine supplementation during IVM improves frequencies of nuclear maturation and preimplantation development of dromedary camel oocytes following IVF. Theriogenology 81:1286-1292.

Fulka J Jr, Leibfried-Rutledge ML, First NL. 1991. Effect of 6-dimethylaminopurine on germinal vesicle breakdown of bovine oocytes. Mol. Reprod. Dev. 29:379-384.

Gilchrist RB. 2011. Recent insights into oocyte-follicle cell interactions provide opportunities for the development of new approaches to in vitro maturation. Reprod. Fertil. Dev. 23:23-31.

Herrick JR. 2019. Assisted reproductive technologies for endangered species conservation: developing sophisticated protocols with limited access to animals with unique reproductive mechanisms. Biol. Reprod. 100:1158-1170.

Huang S, Ding C, Mai Q, Xu Y, Zhou C. 2016. Inhibition of Rho-associated protein kinase increases the ratio of formation of blastocysts from single human blastomeres. Mol. Med. Rep. 13:2046-2052.

Kafi M, Mesbah F, Nili H, Khalili A. 2005. Chronological and ultrastructural changes in camel (Camelus dromedarius) oocytes during in vitro maturation. Theriogenology 63:24582470 .

Kruip TA, Pieterse MC, van Beneden TH, Vos PL, Wurth YA, Taverne MA. 1991. A new method for bovine embryo production: a potential alternative to superovulation. Vet. Rec. 128:208-210.

Li HJ, Sutton-McDowall ML, Wang X, Sugimura S, Thompson JG, Gilchrist RB. 2016. Extending prematuration with cAMP modulators enhances the cumulus contribution to oocyte antioxidant defence and oocyte quality via gap junctions. Hum. Reprod. 31:810-821.

Lonergan P, Dinnyes A, Fair T, Yang X, Boland M. 2000. Bovine oocyte and embryo development following meiotic inhibition with butyrolactone I. Mol. Reprod. Dev. 57:204-209.

Lonergan P and Fair T. 2016. Maturation of oocytes in vitro. Annu. Rev. Anim. Biosci. 4:255-268.

Lonergan P, Khatir H, Carolan C, Mermillod P. 1997. Bovine blastocyst production in vitro after inhibition of oocyte meiotic resumption for 24 h. J. Reprod. Fertil. 109:355-365.

Maziero RRD, Guaitolini CRF, Paschoal DM, Crespilho AM,
Monteiro BA, Lima JS, Sestari DAO, Landim-Alvarenga FDC. 2020. Treatment with roscovitine and butyrolactone I prior to in vitro maturation alters blastocyst production. Zygote 28:24-31.

Mermillod P, Tomanek M, Marchal R, Meijer L. 2000. High developmental competence of cattle oocytes maintained at the germinal vesicle stage for 24 hours in culture by specific inhibition of MPF kinase activity. Mol. Reprod. Dev. 55:8995.

Mesbah F, Kafi M, Nili H. 2016. Cumulus cell expansion and first polar body extrusion during in vitro oocyte maturation in relation to morphological and morphometric characteristics of the dromedary camel ovary. Reprod. Domest. Anim. 51:916-923.

Moawad AR, Ghoneim IM, Darwish GM, Badr MR, El-Badry DA, EL-Wishy ABA. 2020. Factors affecting in vitro embryo production: insights into dromedary camel. J. Anim. Reprod. Biotechnol. 35:119-141.

Moulavi F and Hosseini SM. 2019. Effect of macromolecule supplement on nuclear and cytoplasmic maturation, cryosurvival and in vitro embryo development of dromedary camel oocytes. Theriogenology 132:62-71.

O’Brien MJ, Pendola JK, Eppig JJ. 2003. A revised protocol for in vitro development of mouse oocytes from primordial follicles dramatically improves their developmental competence. Biol. Reprod. 68:1682-1686.

Pincus G and Enzmann EV. 1935. The comparative behavior of mammalian eggs in vivo and in vitro: $\mathrm{I}$. The activation of ovarian eggs. J. Exp. Med. 62:665-675.

Russo R, Monaco D, Rubessa M, El-Bahrawy KA, El-Sayed A, Martino NA, Beneult B, Ciannarella F, Dell'Aquila ME, Lacalandra GM, Filioli Uranio M. 2014. Confocal fluorescence assessment of bioenergy/redox status of dromedary camel (Camelus dromedarius) oocytes before and after in vitro maturation. Reprod. Biol. Endocrinol. 12:16.

Saadeldin IM, Swelum AA, Elsafadi M, Mahmood A, Yaqoob $\mathrm{SH}$, Alfayez M, Alowaimer AN. 2019. Effects of all-trans retinoic acid on the in vitro maturation of camel (Camelus dromedarius) cumulus-oocyte complexes. J. Reprod. Dev. 65:215-221.

Sanchez F, Le AH, Ho VNA, Romero S, Van Ranst H, De Vos M, Gilchrist RB, Ho TM, Vuong LN, Smitz J. 2019. Biphasic in vitro maturation (CAPA-IVM) specifically improves the developmental capacity of oocytes from small antral follicles. J. Assist. Reprod. Genet. 36:2135-2144.

Singh B, Mal G, Gautam SK, Mukesh M. 2019. Reproduction biotechnology in camelids. In: Singh B, Mal G, Gautam SK, Mukesh M (Eds.), Advances in Animal Biotechnology, Springer, Cham, pp. 145-153.

Sirard MA. 1990. Temporary inhibition of meiosis resumption in vitro by adenylate cyclase stimulation in immature bovine oocytes. Theriogenology 33:757-767.

Skidmore JA. 2003. The main challenges facing camel reproduction research in the 21st century. Reprod. Suppl. 61:3747. 
Skidmore JA. 2019. The use of some assisted reproductive technologies in old world camelids. Anim. Reprod. Sci. 207:138145.

Soto-Heras S, Menéndez-Blanco I, Catalá MG, Izquierdo D, Thompson JG, Paramio MT. 2019a. Biphasic in vitro maturation with C-type natriuretic peptide enhances the developmental competence of juvenile-goat oocytes. PLoS One 14:e0221663.

Soto-Heras S, Paramio MT, Thompson JG. 2019b. Effect of prematuration with C-type natriuretic peptide and 3-isobutyl1-methylxanthine on cumulus-oocyte communication and oocyte developmental competence in cattle. Anim. Reprod. Sci. 202:49-57.

Tukur HA, Aljumaah RS, Swelum AA, Alowaimer AN, Saadeldin IM. 2020a. The making of a competent oocyte - a review of oocyte development and its regulation. J. Anim. Reprod. Biotechnol. 35:2-11.

Tukur HA, Aljumaah RS, Swelum AA, N Alowaimer A, Abdelrahman M, Saadeldin IM. 2020b. Effects of short-term inhibition of Rho kinase on dromedary camel oocyte in vitro maturation. Animals (Basel) 10:750.

Vuong LN, Le AH, Ho VNA, Pham TD, Sanchez F, Romero S, De Vos M, Ho TM, Gilchrist RB, Smitz J. 2020. Live births after oocyte in vitro maturation with a prematuration step in women with polycystic ovary syndrome. J. Assist. Reprod. Genet. 37:347-357.

Wani NA and Hong SB. 2020. Effect of roscovitine pretreatment on in vitro maturation of oocytes and their subsequent developmental after chemical activation in dromedary camel
(Camelus dromedarius). Theriogenology 157:176-180.

Wani NA and Nowshari MA. 2005. Kinetics of nuclear maturation and effect of holding ovaries at room temperature on in vitro maturation of camel (Camelus dromedarius) oocytes. Theriogenology 64:75-85.

Wani NA and Wernery U. 2010. In vitro maturation of dromedary (Camelus dromedarius) oocytes: effect of different protein supplementations and epidermal growth factor. Reprod. Domest. Anim. 45:e189-e193.

Wert SE and Larsen WJ. 1989. Meiotic resumption and gap junction modulation in the cultured rat cumulus-oocyte complex. Gamete Res. 22:143-162.

Yaqoob SH, Saadeldin IM, Swelum AA, Alowaimer AN. 2017. Optimizing camel (Camelus dromedarius) oocytes in vitro maturation and early embryo culture after parthenogenetic activation. Small Rumin. Res. 153:81-86.

Zhang M, Zhang CX, Pan LZ, Gong S, Cui W, Yuan HJ, Zhang WL, Tan JH. 2017. Meiotic arrest with roscovitine and follicular fluid improves cytoplasmic maturation of porcine oocytes by promoting chromatin de-condensation and gene transcription. Sci. Rep. 7:11574.

Zhang Y, Duan X, Xiong B, Cui XS, Kim NH, Rui R, Sun SC. 2014. ROCK inhibitor Y-27632 prevents porcine oocyte maturation. Theriogenology 82:49-56.

Zhu S, Jia YJ, Pan LZ, Gong S, Sun MJ, Wang GL, Luo MJ, Tan JH. 2020. Meiotic block with roscovitine improves competence of porcine oocytes by fine-tuning activities of different cyclin-dependent kinases. J. Cell. Physiol. 235:7530-7540. 